\title{
DENSIDADE DE PLANTIO DE PALMITEIRO EM REGIME DE SOMBREAMENTO PERMANENTE (1)
}

\author{
MARILENE LEÃO ALVES BOVI (2, 4), LUIS ALBERTO SÁES (3), \\ MÁRIO CARDOSO $\left({ }^{2}\right)$ O JOSÉ CIONE $\left({ }^{3}\right)$
}

\begin{abstract}
RESUMO
Estudou-se o comportamento do palmiteiro (Euterpe edulis Mart.) plantado sob mata nativa raleada, em diferentes densidades de plantio, nas condições do Vale do Ribeira, SP. Avaliou-se o crescimento vegetativo das plantas pelos seguintes parâmetros: circunferência da planta a diferentes alturas, número de folhas funcionais, comprimento da quarta folha e altura da planta. Avaliou-se também a produção, através do peso, diâmetro e comprimento do palmito obtido. A maior produção de palmito por área foi alcançada nos espaçamentos $1,5 \times 1,0$ e 1,0 $\times 1,0 \mathrm{~m}$.
\end{abstract}

Termos de indexaçāo: palmiteiro, Euterpe edulis Mart., densidade de plantio, desenvolvimento vegetativo e produção.

(1) Trabalho apresentado no $5^{\circ}$ Congresso Florestal Brasileiro, Olinda, PE, em novembro de 1986. Recebido para publicação em 9 de dezembro de 1986.

(2) Seçâo de Plantas Tropıcais, Instituto Agronômico (IAC). Caixa Postal 28, 13001 Campinas (SP).

(3) Estação Experimental de Pariquera-Açu, IAC.

(4) Com bolsa de suplementaçāo do CNPq. 


\section{INTRODUÇÃO}

O palmiteiro (Euterpe edulis Mart.) tem por hábitat as matas pluviais da Costa Atlântica e do Planalto dos Estados do Sul e Sudeste do Brasil, abrangendo ainda parte do Paraguai e Argentina (LEĀO \& CARDOSO, 1974, e MACEDO, 1970). É, sem dúvida, uma das poucas plantas comercialmente exploradas que podem ser cultivadas em uma floresta nativa, em harmonia com seu ecossistema. A propósito, a exploração dessa espécie para palmito vem sendo feita desde épocas remotas. Segundo CASTRO \& VALERY (1954), os primeiros consumidores desse vegetal foram os índios, que já o empregavam em sua alimentação na época do descobrimento do Brasil. Com o advento da industrialização e aprimoramento das técnicas de processamento, o palmito passou de produto de consumo e comercialização limitado em nosso País, a produto de aceitação internacional (TEIXEIRA, 1966) e franca exportação (WASHINGTON, 1962). No entanto, a exploração basicamente extrativa, predatória $e$ indiscriminada tem causado acentuado decréscimo das suas reservas naturais. Entre os vários aspectos envolvidos, o ciclo bastante longo da espécie e a falta de normas técnicas de cultivo baseadas em resultados de pesquisa contribuem, sobremaneira, para a permanência desse status.

O Instituto Agronômico de Campinas, desde o início dos anos 70 , vem tentando suprir essa falha com uma série de estudos nas áreas de fitotecnia, melhoramento genético, fitossanidade, envolvendo essa (BOVI \& CARDOSO, 1978) e outras espécies do gênero Euterpe (BOVl, 1984). O ciclo longo dessas palmeiras, porém, tem reflexos diretos na obtenção de resultados de pesquisa que só agora começam a surgir.

No presente trabalho, relatam-se resultados obtidos em experimento de densidade de plantio com o palmiteiro sob mata nativa, na região do Vale do Ribeira, SP. Trata-se de um estudo básico e fundamental, dada a inexistência de informações técnicas no setor, o qual vem proporcionar melhor conhecimento do comportamento da espécie Euterpe edulis e subsidios para sua exploração racional.

\section{MATERIAL E MÉTODOS}

Instalou-se, em 1972, um ensaio de espaçamento de palmiteiro sob floresta latifoliada tropical perenifólia na Estação Experimental de Pariquera-Açu $\left(24^{\circ} 36^{\prime} \mathrm{S}\right.$. e $48^{\circ} 52^{\prime} \mathrm{W}$.), pertencente ao Instituto Agronômico. A mata foi previamente raleada dos arbustos e vegetação do extrato secundário, o que proporcionou um sombreamento inicial ao redor de $50 \%$.

Nos quadros 1 e 2 encontram-se os principais dados climáticos do local do experimento, desde o plantio até a colheita. O clima da região é caracterizado como do tipo "Cf", tropical, quente e úmido, sem estação seca, com precipitação pluviométrica anual normal de $1.583 \mathrm{~mm}$, evapotranspiração potencial normal de 
$1.140 \mathrm{~mm}$, excedente nornal de $447 \mathrm{~mm}$ e deficiência hídrica nula. A temperatura média de verão normal é de $25,6^{\circ} \mathrm{C}$ e, de inverno, $19,1^{\circ} \mathrm{C}$.

O solo do local do experimento pertence à unidade Pariquera-Açu II, sendo classificado como latossolo amarelo podzólico álico, A moderado, textura argilosa. $E$ ácido, com baixos teores de nutrientes e alta saturação por aluminio. SAKAI \& LEPSCH (1984) descrevem com detalhes sua composição e principais características.

O experimento foi delineado em blocos ao acaso com quatro densidades de plantio $(1,0 \times 1,0 ; 1,5 \times 1,0 ; 2,0 \times 1,0$ e 2,0 $\times 1,5 \mathrm{~m})$, quatro repetiçōes $e$ 32 plantas por parcela, sendo 12 úteis.

Efetuou-se o plantio por mudas obtidas pela semeadura em sacos plásticos contendo terra peneirada, mantidos em condições de viveiro durante oito meses: as plantas tinham então $30 \mathrm{~cm}$ de altura $e$ apresentavam três a quatro folhas funcionais. Para a formação das mudas, colheram-se as sementes de palmiteiros adultos nativos na própria Estação Experimental, sadias e em estádio uniforme de maturação.

QUADRO 1. Dados climáticos obtidos na Estação Experimental de Pariquera-Açu, SP, no período $1972-84\left({ }^{(}\right)$

\begin{tabular}{ccc}
\hline Ano & $\begin{array}{c}\text { Temperatura } \\
\text { média }\end{array}$ & $\begin{array}{c}\text { indice } \\
\text { pluviométrico }\end{array}$ \\
\hline 1972 & 0 C & $\mathrm{mm}$ \\
1973 & 22,1 & $1.425,1$ \\
1974 & 22,1 & $2.012,4$ \\
1975 & 21,4 & $1.251,0$ \\
1976 & 21,7 & $1.689,0$ \\
1977 & 21,5 & $1.748,8$ \\
1978 & 22,7 & $1.138,2$ \\
1979 & 21,8 & $1.004,2$ \\
1980 & 21,3 & $1.377,4$ \\
1981 & 22,2 & $1.482,6$ \\
1982 & 22,1 & $1.338,3$ \\
1983 & 22,1 & $1.646,0$ \\
1984 & 21,0 & $2.020,7$ \\
\hline
\end{tabular}

(1) Dados fornecidos pela Seção de Climatologia Agrícola do IAC. 
QUADRO 2. Dados climáticos mensais (média) obtidos na E.E. de Pariquera-Açu no período $1972-84\left(^{1}\right)$

\begin{tabular}{lccccc}
\hline \multirow{2}{*}{ Mês } & \multicolumn{3}{c}{ Temperatura } & $\begin{array}{c}\text { Índice } \\
\text { pluviométrico }\end{array}$ & $\begin{array}{c}\text { Dias de } \\
\text { precipitação }\end{array}$ \\
\cline { 2 - 4 } & $\begin{array}{l}\text { Média das } \\
\text { máximas }\end{array}$ & $\begin{array}{c}\text { Média das } \\
\text { mínimas }\end{array}$ & Média & & \\
\cline { 2 - 3 } Janeiro & 30,1 & 20,7 & 25,4 & 202,3 & 18 \\
Fevereiro & 30,8 & 21,3 & 26,1 & 170,0 & 14 \\
Março & 29,5 & 20,6 & 25,1 & 186,9 & 16 \\
Abril & 26,8 & 17,8 & 22,3 & 98,7 & 13 \\
Maio & 25,2 & 15,9 & 20,6 & 103,6 & 10 \\
Junho & 23,6 & 14,0 & 18,8 & 80,9 & 10 \\
Julho & 21,3 & 13,3 & 18,2 & 76,5 & 11 \\
Agosto & 23,5 & 14,1 & 18,8 & 72,4 & 13 \\
Setembro & 23,6 & 15,2 & 19,4 & 76,8 & 15 \\
Outubro & 25,3 & 16,7 & 21,0 & 135,0 & 14 \\
Novembro & 27,3 & 18,0 & 22,6 & 114,7 & 17 \\
Dezembro & 29,4 & 20,0 & 24,7 & 165,3 & \\
\hline
\end{tabular}

(1) Dados fornecidos pela Seção de Climatologia Agrícola do IAC.

As avaliações do desenvolvimento vegetativo das plantas foram feitas periodicamente após o primeiro ano de plantio, consistindo nos seguintes parâmetros: circunferência da planta ao nivel do coleto e a 10,50 e $130 \mathrm{~cm}$ de altura do solo; número de folhas funcionais; número de folhas emitidas entre duas mediçōes consecutivas e comprimento da quarta folha (BOVI \& CARDOSO, 1979).

Não se realizaram adubações, resumindo-se os tratos culturais a roçadas periódicas até o terceiro ano de plantio.

Após três anos de plantio, fez-se a avaliação individual da altura das plantas de cada tratamento, medida do coleto até o ponto de inserção da folha mais nova.

Realizou-se a colheita do ensaio em 1984, doze anos após o plantio. As plantas foram cortadas e os respectivos palmitos, após separação dos estipes e folhas, etiquetados e levados ao laboratório. $O$ "creme" ou palmito propriamente dito foi extraido, pesado e medido individualmente (diâmetro e comprimento), seguindo metodologia recomendada pelo Instituto de Tecnologia de Alimentos (CAMPOS et al., 1978, e FERREIRA et al., 1976). 
Os dados foram estatisticamente estudados através da análise de variância e do teste de Tukey (STEEL \& TORRIE, 1960), e as correlaçōes entre alguns parâmetros, calculadas, assumindo-se um modelo linear.

\section{RESULTADOS}

Nas figuras 1 e 2 encontram-se, respectivamente, os dados de circunferência das plantas ao longo da duração do experimento e o número de folhas funcionais. Entre $\circ 11^{\circ}$ e o $28^{\circ}$ mês após o plantio, os incrementos na circunferência dos quatro tratamentos foram lineares, a saber: 0,$60 ; 0,69 ; 0,70$ e 0,67 $\mathrm{cm} /$ mês (valores de $\mathrm{r}^{2}: 0,991 ; 0,999 ; 0,996$ e 0,994 ), respectivamente, para os espaçamentos de $1,0 \times 1,0 ; 1,5 \times 1,0 ; 2,0 \times 1,0$ e $2,0 \times 1,5 \mathrm{~m}$.

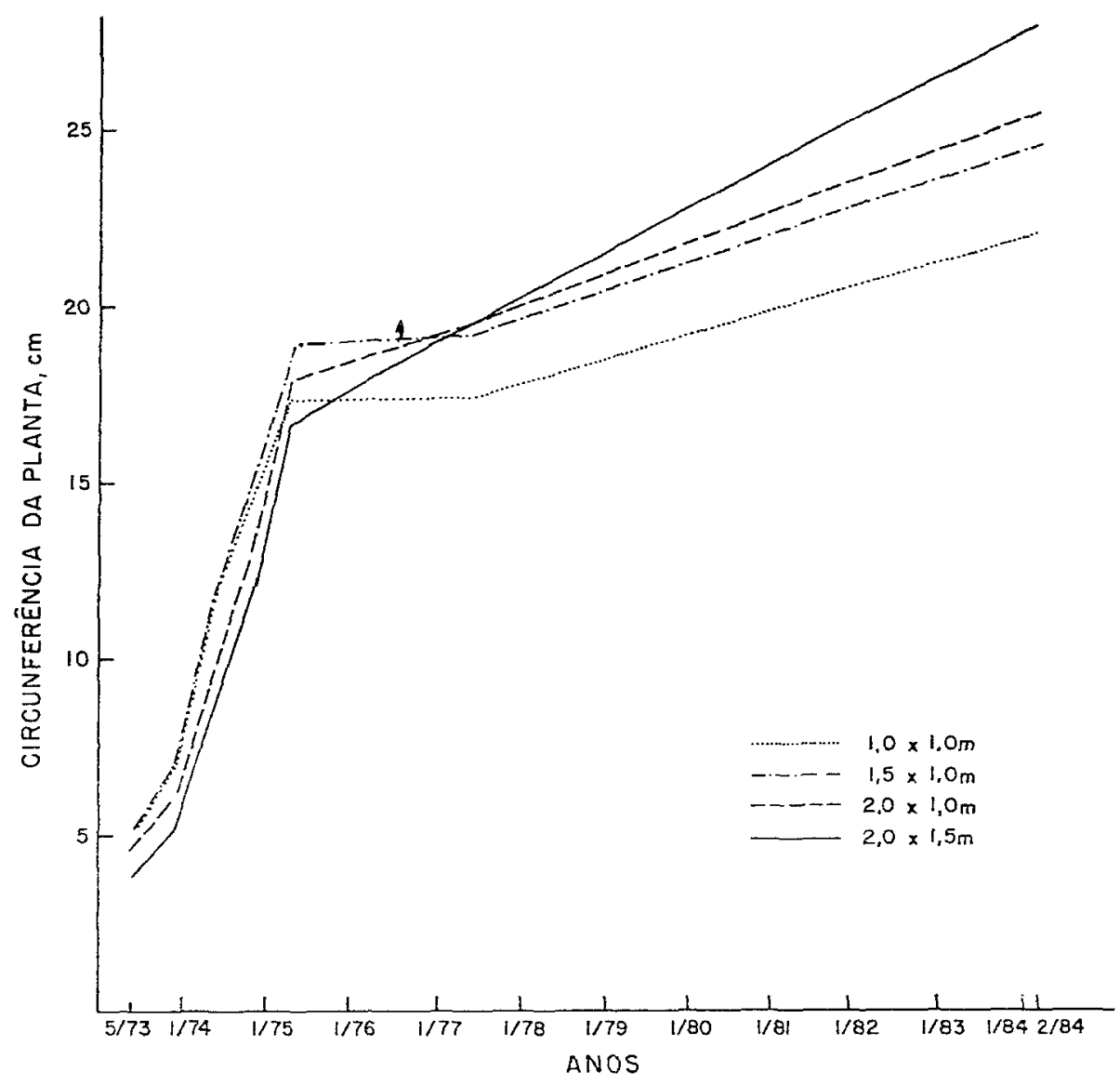

Figura 1. Circunferência do palmiteiro para os diversos espaçamentos (Média de quatro repetiçôes) 


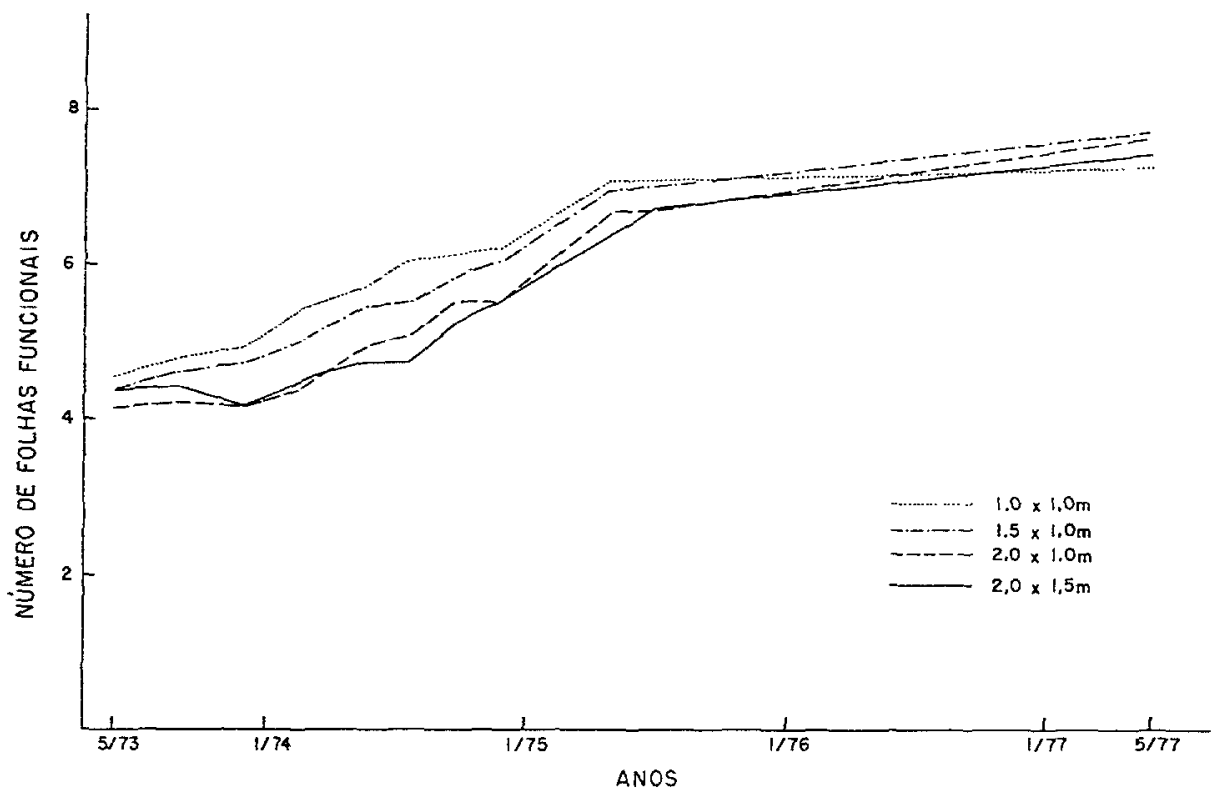

Figura 2. Número de folhas tuncionais (vivas) obtido nos diversos tratamentos (Média de quatro repetições)

Esse aumento linear e acentuado da circunferência pode ser explicado pela ausência de competição entre as plantas. Decorridos onze meses do plantio, as plantas possuiam ao redor de quatro folhas funcionais cada uma, atingindo aos 28 meses cerca de seis folhas. A interceptação de luz pelas folhas, devido a sua disposição espiralada, não constituiu fator limitante, pois não ocorreu o auto-sombreamento delas. Os fatores de solo e água também não foram limitantes, em vista do porte ainda baixo das palmeiras.

A partir do $28^{\circ}$ mês do plantio, os acréscimos na circunferência foram menores, provavelmente pela crescente competiçāo entre as plantas, atingindo, na colheita, 21,80; 24,$50 ; 25,32$ e $27,78 \mathrm{~cm}$ para os espaçamentos de $1,0 \times 1,0$; $1,5 \times 1,0 ; 2,0 \times 1,0$ e 2,0 $\times 1,5$ m respectivamente.

O número de folhas funcionais foi anotado no periodo abril de 1973-maio de 1977. A partir dessa data, tornou-se inviável a contagem de folhas funcionais dada a altura das palmeiras e o entrelaçamento das copas. Não foram observadas, durante esse periodo, diferenças significativas entre os tratamentos. Na contagem inicial, o número de folhas esteve entre 4 e 5 , alcançando ao redor de 7 até onde foi possivel contá-las. Foi feita a contagem final de folhas vivas na colheita (2/84), tendo-se constatado que as plantas apresentavam de 14 
a 17 folhas. Portanto, após o quinto ano de plantio definitivo, as folhas apresentaram um incremento de 1 a 1,5 folha funcional por ano.

A figura 3 apresenta os dados do comprimento da quarta folha (a contar da mais nova) para os diferentes tratamentos, de maio 73 até junho 75 . Após esse período, não foi possível a realização dessas medidas. Não se detectaram diferenças significativas entre os espaçamentos ao nivel de $0,05 \%$. O comprimento da quarta folha, no inicio das medidas, estava entre 10 e $20 \mathrm{~cm}$, atingindo entre 60 e $70 \mathrm{~cm}$ após 27 meses.

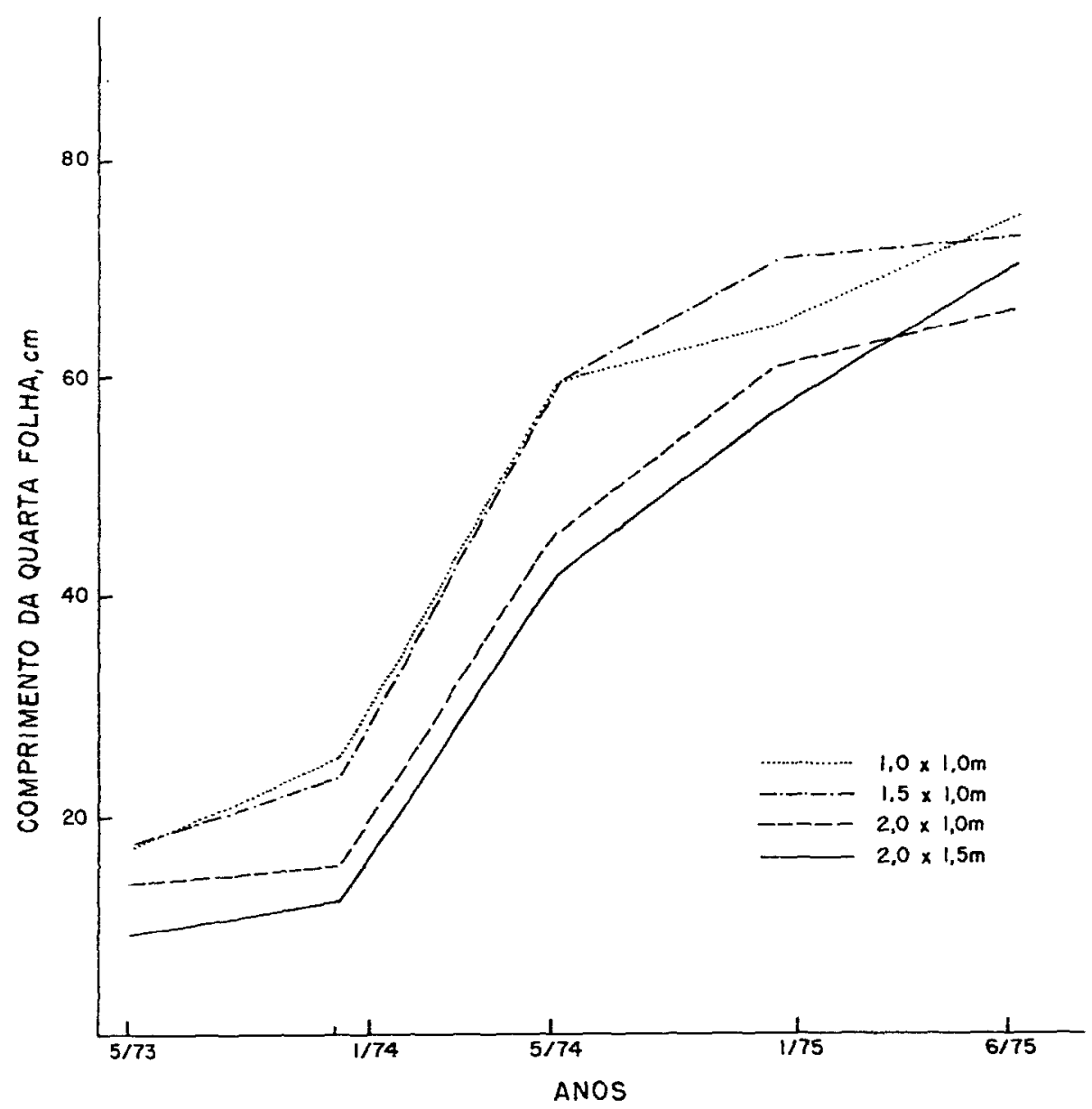

Figura 3. Comprimento da quarta folha obtido nos diversos espaçamentos (Média de quatro repetiçōes) 
No quadro 3 , encontram-se os dados referentes à altura das plantas, no terceiro ano de campo. Não se detectaram diferenças significativas entre as alturas das plantas dos diversos espaçamentos, as quais variaram de 135 a $169 \mathrm{~cm}$ para os tratamentos $2,0 \times 1,0$ e 1,0 $\times 1,0 \mathrm{~m}$ respectivamente.

A colheita do ensaio foi efetuada em fevereiro de 1984, encontrando-se seus resultados no quadro 4 . A análise de variância dos dados revelou diferenças significativas, ao nível de $0,01 \%$, para todos os parâmetros. Na comparação de médias, através do teste de Tukey $(0,05)$, constatou-se que as circunferências das plantas, a $130 \mathrm{~cm}$ do solo, para os tratamentos $2,0 \times 1,5$ e 2,0 $\times 1,0 \mathrm{~m}$ foram maiores do que para o espaçamento $1,0 \times 1,0 \mathrm{~m}$.

Com relaçăo ao diâmetro do palmito, os resultados foram similares para as medidas efetuadas na base, meio e ápice. $O$ diâmetro médio do palmito no espaçamento 2,0 $\times 1,5 \mathrm{~m}$ foi maior do que no $1,0 \times 1,0 \mathrm{~m}$, com diferenças superiores a $1,0 \mathrm{~cm}$. Esse fator assume importância com relação ao processamento e embalagem do produto.

QUADRO 3. Altura das plantas nos diversos espaçamentos no terceiro ano de cultivo. Média de quatro repetiçōes $(\bar{x})$

\begin{tabular}{cc}
\hline Espaçamento & $\begin{array}{c}\text { Altura } \\
\bar{x} \pm \mathrm{s}(\overline{\mathrm{x}})\left({ }^{1}\right)\end{array}$ \\
\hline$m$ & $\mathrm{~cm}$ \\
$2,0 \times 1,5$ & $143,53 \pm 9,96 \mathrm{a}\left({ }^{2}\right)$ \\
$2,0 \times 1,0$ & $135,15 \pm 10,67 \mathrm{a}$ \\
$1,5 \times 1,0$ & $143,63 \pm 10,77 \mathrm{a}$ \\
$1,0 \times 1,0$ & $169,25 \pm 11,68 \mathrm{a}$ \\
\hline $\mathrm{F}$ tratamento $=0,716 \mathrm{~ns}$ & \\
$\mathrm{~F}$ bloco $=0,82 \mathrm{~ns}$ & \\
CV $=23,63 \%$ & \\
dims Tukey $=77,22 \mathrm{~cm}$ & \\
\hline
\end{tabular}

(1) Erro padrão da médıa. $s(\bar{x})=\frac{s}{\sqrt{n}}$, onde $s$ é o desvio-padrão e $n$, o número de plantas.

(2) Médias seguidas da mesma letra năo diferem estatisticamente pelo teste de Tukey a $5 \%$. 


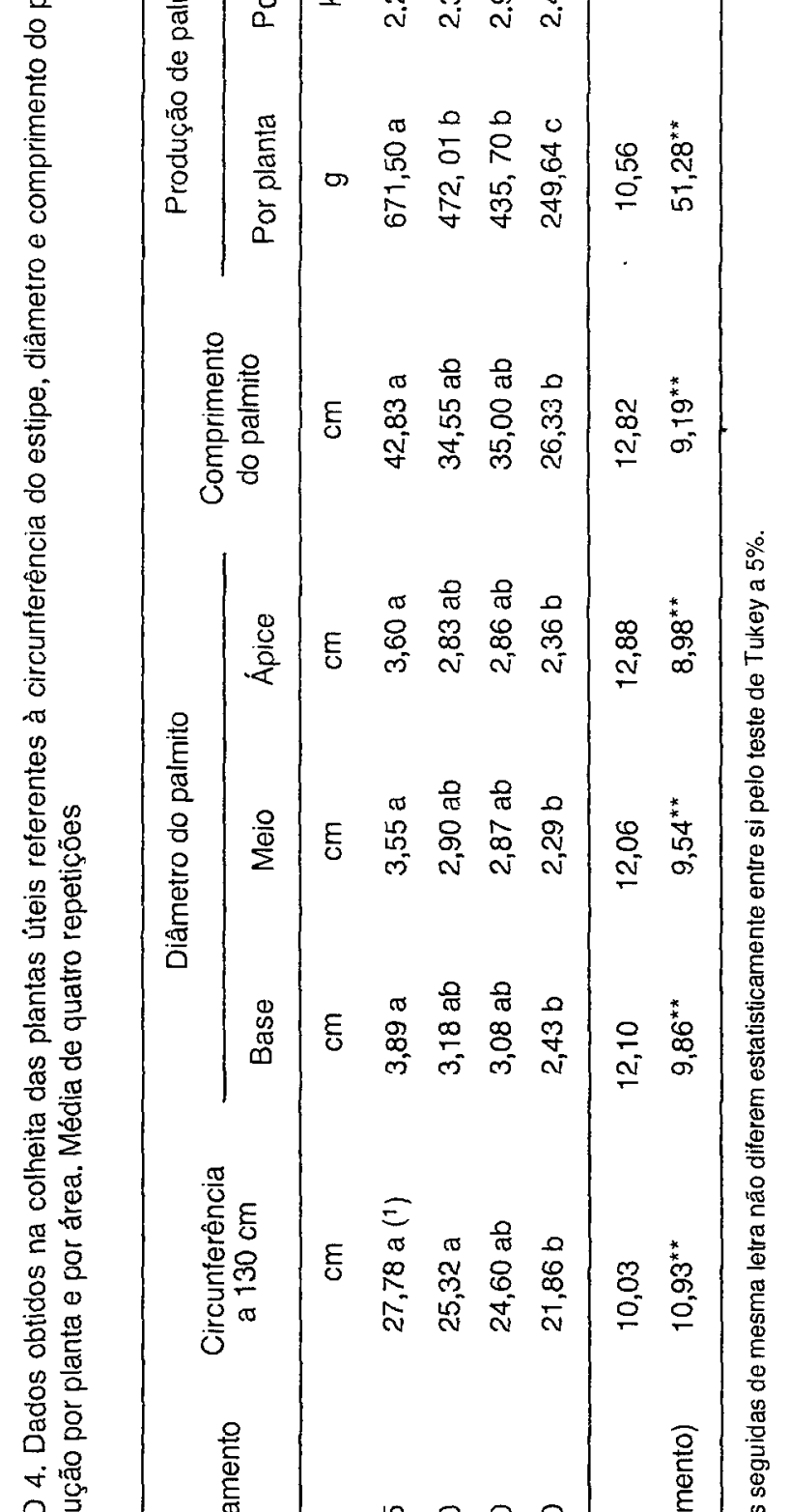


O comprimento do palmito também apresentou-se, em média, $16,5 \mathrm{~cm}$ maior no espaçamento $2,0 \times 1,5$, quando comparado com o $1,0 \times 1,0 \mathrm{~m}$.

Considerando-se o peso do palmito por planta, o tratamento $2,0 \times 1,5 \mathrm{~m}$ mostrou-se superior aos demais, sendo seguido pelos espaçamentos $2,0 \times 1,0 \mathrm{e}$ $1,5 \times 1,0 \mathrm{~m}$, que não diferiram entre si e foram superiores ao espaçamento $1,0 \times$ $\times 1,0 \mathrm{~m}$.

Entretanto, do ponto de vista de produção com base em área plantada, o espaçamento $1,5 \times 1,0$ não diferiu estatisticamente do 1,0 $\times 1,0 \mathrm{~m}$, mas foi superior aos demais, produzindo, em média, $2.905 \mathrm{~kg}$ de palmito por hectare.

Efetuaram-se diversos estudos de correlação visando identificar relações entre medidas da planta e do palmito. Devido à facilidade de execução e à significância obtida, foi escolhida a circunferência da planta adulta a $130 \mathrm{~cm}$ de altura do solo. Obtiveram-se correlações lineares positivas, significativas ao nivel de $0,01 \%$ dessa medida com o peso do palmito para todos os tratamentos. No quadro 5 são apresentados os dados obtidos nessas análises. $O$ incremento do peso de palmito para cada centímetro de circunferência só é válido a partir do valor minimo teórico igual à produção zero de paimito. As análises indicaram uma produção de 26,8 a 37,7 gramas de palmito para cada centímetro de circunferência da planta, a $130 \mathrm{~cm}$ do solo, acima da circunferência mínima teórica.

QUADRO 5. Correlação entre circunferência da planta a $130 \mathrm{~cm}$ do solo e produçăo de palmito por planta para os diversos tratamentos

\begin{tabular}{cccc}
\hline Espaçamento & $\begin{array}{c}\text { Circunferência } \\
\text { mínima } \\
\text { teórica }\end{array}$ & $\begin{array}{c}\text { Gramas de paimito/ } \\
\text { centimetro de } \\
\text { circunferência (1) }\end{array}$ & $\begin{array}{c}\text { Coeficiente de } \\
\left.\text { determinação ( }{ }^{2}\right)\end{array}$ \\
\hline $\mathrm{cm}$ & $\mathrm{g} / \mathrm{cm}$ & \\
$2,0 \times 1,5$ & 12,8 & 37,7 & $0,873^{\star \star}$ \\
$2,0 \times 1,0$ & 10,6 & 34,1 & $0,886^{\star \star}$ \\
$1,5 \times 1,0$ & 9,5 & 26,8 & $0,941^{\star \star}$ \\
$1,0 \times 1,0$ & 9,0 & 30,3 & $0,782^{\star \star}$ \\
\hline
\end{tabular}

(1) Válido para valores de circunferência acima da mínima teórica para os respectivos espaçamentos. 


\section{DISCUSSÃO}

Devido à carência de dados de pesquisa e ao pioneirismo na área, a escolha dos espaçamentos utilizados no presente experimento foi baseada em observaçōes de povoamentos naturais de palmiteiro, levando-se em consideração a projeção das copas $e$ a densidade de plantas encontradas.

A medida da circunferência da planta a $10 \mathrm{~cm}$ do solo mostrou-se como um parâmetro viável até aproximadamente três anos após o plantio. A partir dessa idade, a mesma medida, feita a $50 \mathrm{~cm}$, mostrou-se mais confiável, devido à formação do platô radicular. A partir do quinto ano, a medida da circunferência fol efetuada a $130 \mathrm{~cm}$ da altura do solo (evidentemente, a mais prática de ser obtida). Os dados de circunferência - Figura 1 - são resultantes da composição dessas três medidas.

No presente trabalho, constatou-se que a mediçāo da circunferência para a análise do crescimento do palmiteiro pode ser feita duas vezes ao ano, dando uma idéia precisa do desenvolvimento dessa palmeira.

A medida da circunferência do palmiteiro mostrou ser um dos parâmetros mais seguros para a avaliação indireta da produtividade da planta (peso do palmito) e deve merecer estudos mais detalhados nos futuros trabalhos com essa palmeira.

Outro fator utilizado para avaliar o comportamento da planta nas diferentes densidades de plantio foi o número de folhas funcionais. A utilização desse parâmetro deve-se ao fato de o palmito se constituir de folhas jovens, em desenvolvimento, envoltas pelas bainhas das mais velhas (FERREIRA et al., 1976). Entretanto, a tomada desse parâmetro após o terceiro ano de campo é difícil, devido à altura das plantas e ao entrelaçamento das copas.

Q: comprimento da quarta folha foi utilizado no presente estudo para comparação dos tratamentos de densidade de plantio com base em trabalhos de avaliação precoce de coqueiro (JAUNET, 1968). Esse parâmetro, porém, não apresentou sensibilidade suficiente para detectar diferenças entre as diversas densidades de plantio no período em que foi utilizado. Como no caso anterior, as medidas do comprimento da quarta folha só foram viáveis até o terceiro ano de campo.

Pelos resultados obtidos, pode-se inferir que a densidade ótima de plantio para a espécie $E$. edulis está compreendida entre as densidades aqui estudadas. A menor produção de palmito por planta, obtida nos tratamentos mais adensados, é, de certa forma, atenuada quando se considera a produção por unidade de área plantada, em face da existência de maior número de plantas.

Com relação a futuros experimentos, é aconselhável a utilização de amostragens periódicas destrutivas para determinação do ponto de máximo retorno econômico, apesar da necessidade de uma área bem maior de experimentação. 


\title{
5. CONCLUSŌES
}

1) A maior produção de paimito por área, em magnitude, foi obtida no espaçamento $1,5 \times 1,0 \mathrm{~m}$, sem diferir estatisticamente do espaçamento $1,0 \times 1,0 \mathrm{~m}$, com 2905 e $2496 \mathrm{~kg}$ de palmito por hectare respectivamente.

2) A produção de palmito com base em plantas individuais apresentou diferenças acentuadas entre as diversas densidades de plantio, variando, em média, de 249,64 a 671,50 gramas de palmito por planta, para os espaçamentos $1,0 \times 1,0$ e 2,0 $\times 1,5$ m respectivamente.

3) As diferentes densidades de plantio provocaram mudanças pronunciadas no comprimento e diâmetro do palmito, especialmente entre os espaçamentos $2,0 \times 1,5$ e $1,0 \times 1,0 \mathrm{~m}$.

4) A circunferência da planta a $130 \mathrm{~cm}$ de altura do solo mostrou-se altamente correlacionada com a produção de palmito por planta: 26,8 a 37,7 gramas de palmito por centímetro de circunferência, acima da mínima teórica.

5) Não se detectaram diferenças significativas entre os tratamentos com relação aos parâmetros: número de folhas funcionais, comprimento da quarta folha e altura das plantas.

\section{SUMMARY \\ PLANTING DENSITY OF EUTERPE EDULIS MART. UNDER SHADING CONDITIONS}

\begin{abstract}
A spacing experiment with the species Euterpe edulis Mart. was carried out in the rain forest of the Vale do Ribeira region in the State of São Paulo, Brazil. In order to evaluate growth, several parameters were used: plant height, number of green leaves, length of the fourth leaf and girth at $130 \mathrm{~cm}$ high. Maximum heart of palm yield was obtained in the $1.5 \times 1.0$ and $1.0 \times 1.0 \mathrm{~m}$ planting density.
\end{abstract}

Index terms: heart of palm, Euterpe edulis Mart., planting density, growth and yield.

\section{REFERÊNCIAS BIBLIOGRÁFICAS}

BOVI, M.L.A. Pesquisas em desenvolvimento com o açaizeiro no Instituto Agronômico. O Agronômico, Campinas, 36(2):155-178, 1984.

\& CARDOSO, M. Pesquisas com o palmiteiro (Euterpe edulis Mart.). Campinas, Instituto Agronômico, 1978. 46p. (Mimeo) 
CAMPOS, S.D.S.; PASCHOALINO, J.E. \& CIAMPI, C.M.S. Influência do tempo de cozimento na textura do palmito. Boletim do ITAL, Campinas, 57:141-157, 1978.

CASTRO, D.P. \& VALERY, P.P.T. Estudos preliminares sobre o valor nutritivo do paimito. Anais da Faculdade de Farmácia e Odontologia, São Paulo, 12:139-142, 1954.

FERREIRA, V.L.P.; MIYA, E.E.; SHIROSE, I.; SILVA, E.A.M. \& HIGHLANDS, M.E. Comparaçāo físico-químico-sensorial do palmito de três espécies de palmeira. Coletânea do ITAL, Campinas, 7(2):389-416, 1976.

JAUNET, J.P. Observations sur la croissance du cocotier. Oleagineaux, 23(4):243-246, 1968.

LEÃO, M. \& CARDOSO, M. Instruçōes sobre o cultivo do palmiteiro. Campinas, IAC-SUDELPA, 1974. 18p.

MACEDO, J.H.P. Palmito, uma grande fonte de divisas. Floresta, Curitiba, 2(3):19-20, 1970.

SAKAI, E. \& LEPSCH, I.F. Levantamento pedológico detalhado da Estação de Pariquera-Açu. Campinas, Instituto Agronômico, 1984. 56p. (Boletim técnico, 83)

STEEL, R.G. \& TORRIE, J.H. Principles and procedures of Statistics. New York, McGraw-Hill, 1960. 481p.

TEIXEIRA, C.G. Palmito - fino alimento vegetal brasileiro é industrializado em condiçōes precárias. Alimentos e Bebidas, São Paulo, 2(3):12-13, 1966.

WASHINGTON. Embaixada do Brasil. Serviço de Propaganda e Extensão Comercial. Palmito: sua exportação para os E.U.A. New York, 1962. 24p. (Série Estudos de Mercado, 13) 